\title{
X-ray diffraction analysis of hydroxyapatite-coated in different plasma gas atmosphere on $\mathrm{Ti}$ and Ti-6Al-4V
}

\author{
Ravindra Kotian ${ }^{1}$, P. Prasad Rao ${ }^{2}$, Prashanthi Madhyastha ${ }^{1}$
}

Correspondence: Dr. Ravindra Kotian

Email: ravindra.kotian@manipal.edu

\author{
'Department of Dental Materials, Manipal College \\ of Dental Sciences, Manipal University, Mangalore, \\ Karnataka, India, \\ ${ }^{2}$ Department of Metallurgical and Materials \\ Engineering, National Institute of Technology \\ Karnataka, Surathkal, Karnataka, India
}

\section{ABSTRACT}

Objective: The aim is to study the effect of plasma working gas on composition, crystallinity, and microstructure of hydroxyapatite (HA) coated on Ti and Ti-6Al-4V metal substrates. Materials and Methods: Ti and Ti-6Al-4V metal substrates were coated with HA by plasma spray using four plasma gas atmospheres of argon, argon/hydrogen, nitrogen, and nitrogen/hydrogen. The degree of crystallinity, the phases present, and microstructure of HA coating were characterized using X-ray diffraction and scanning electron microscopy. Results: Variation in crystallinity and the microstructure of HA coating on plasma gas atmosphere was observed. Micro-cracks due to thermal stresses and shift in the $2 \theta$ angle of HA compared to feedstock was seen. Conclusion: Plasma gas atmosphere has a significant influence on composition, crystallinity, and micro-cracks of HA-coated dental implants.

Key words: Hydroxyapatite, plasma coating, Ti-6AI-4V, titanium, X-ray diffraction

\section{INTRODUCTION}

Plasma spraying is the technique used for coating hydroxyapatite (HA) on metal structural substrates of medical and dental implants. The processing parameters of plasma coating have an influence on the crystallinity, and phase composition of HA and the coated HA found have biological response. ${ }^{[1-4]}$

The performance of plasma sprayed HA coatings depends on adhesion to the metal substrate. This is influenced by microstructural features of the coatings, porosity, degree of deformation of spray particle splats, the presence of micro- and macro-cracks, as well as residual stresses at the coating-substrate interface,

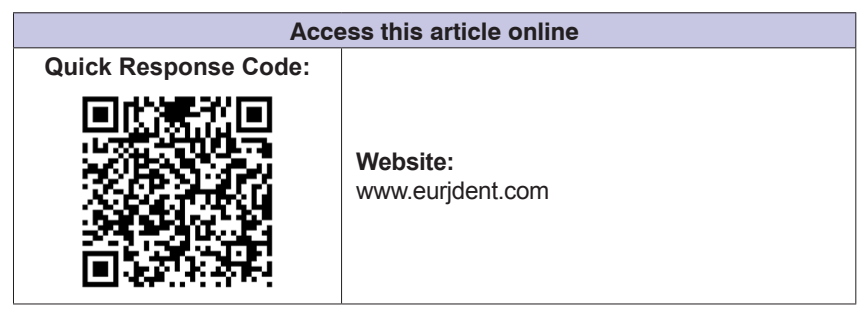

and biochemical resistance against aggressive body fluids.

The medical and dental implants coated with HA should have minimum porosity, good bonding, strong adhesion with the substrate, a high degree of crystallinity and high chemical purity, and structural stability. In the physiological environment, amorphous HA tend to dissolve rapidly. Nearly $60 \%-70 \%$ of HA crystallinity is accepted for biomedical application..$^{[5,6]}$

The plasma spray process is controlled through parameters such as power, current, the distance

This is an open access article distributed under the terms of the Creative Commons Attribution-NonCommercial-ShareAlike 3.0 License, which allows others to remix, tweak, and build upon the work non-commercially, as long as the author is credited and the new creations are licensed under the identical terms.

For reprints contact: reprints@medknow.com

How to cite this article: Kotian R, Rao PP, Madhyastha P. X-ray diffraction analysis of hydroxyapatite-coated in different plasma gas atmosphere on Ti and Ti-6Al-4V. Eur J Dent 2017;11:438-46.

DOI: 10.4103/ejd.ejd_100_17 
between nozzle and substrates, plasma work gas rate, and feed rate. With the advancement of technology and plasma spray gun design, ${ }^{[7]}$ average coating densities, and bond strengths are increasing, and average coating oxide contents are decreasing.

The plasma working gas composition remains same during plasma spray process which is not a basic parameter that is changed during the coating process. However, it is considered to be an important parameter that has an influence on coating properties. ${ }^{[8]}$ For example, a mixture of argon and hydrogen as plasma gas atmosphere gives a good coating. However, when only argon gas used as plasma gas, the powder particles tend to rebound from the flame because of its high viscosity and velocity. Plasma gas composition has an influence on the thickness of coating. For example, nitrogen as plasma gas results in thicker coating when compared to the use of argon gas. Therefore, one can expect the possibility of plasma gas composition having a significant role on the properties of HA coating.

Therefore, this study was aimed to assess the effect of various plasma gas compositions on crystallinity, microstructure and composition of HA by X-ray diffraction (XRD) analysis and scanning electron microscopy (SEM). The plasma gas compositions selected in the present study were argon, nitrogen, argon/hydrogen, and nitrogen/hydrogen.

\section{MATERIALS AND METHODS}

\section{Titanium and Ti-6Al-4V}

Commercially pure titanium (ASTM B 348 Gr. 1), hereafter called Ti 12 and Ti-6Al-4V (ASTM B 348 Gr. 5), hereafter called Ti 31 were obtained from Mishra Dhatu Nigam Ltd., Hyderabad in the form of rods of $8 \mathrm{~mm}$ diameter. These were used as the substrate metal to be coated with HA by plasma spray technique.

\section{Hydroxyapatite}

In the present study, HA was the surface coating material sprayed on Ti 12 and Ti 31 metal substrates. The HA powder was procured from Plasma Biotal Limited, U.K. As reported by the manufacturer, the powder contained HA with minor traces of calcium oxide phosphate and alpha calcium orthophosphate with average particle size of 30 micron and relative crystallinity $97 \%$. The morphology of feedstock HA powder shown in Figure 1 is characterized by a porous structure. The particles are irregular in the shape

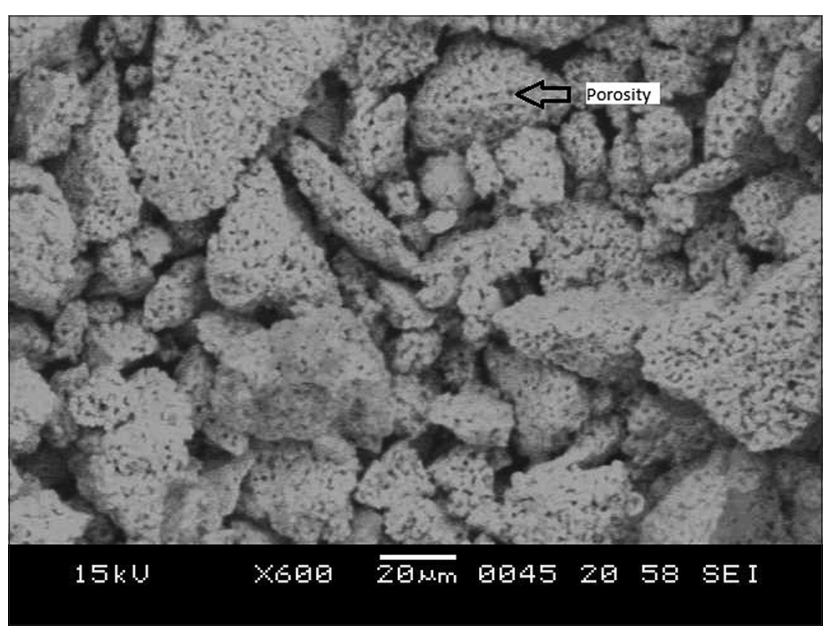

Figure 1: Scanning electron microscopy image of hydroxyapatite powder used as spray material

of varying size with particle mean size of $30 \mu$. The presence of large pores in the HA feedstock means that the process of manufacture does not seem to be followed by any high-temperature densification. This powder was coated on Ti 12 and Ti 31 samples of dimension $100 \mathrm{~mm} \times 6 \mathrm{~mm} \times 4 \mathrm{~mm}$ prepared from the $8 \mathrm{~mm}$ rods procured.

\section{Plasma coating}

Plasma spray processing is a method of giving a material a protective coating through the form of a plasma spray. In the present study, plasma coating of HA was given on Ti 12 and Ti 31 metal substrates. The metallic samples of dimension $100 \mathrm{~mm} \times 6 \mathrm{~mm} \times 4 \mathrm{~mm}$ were prepared from the rods of Ti 12 and Ti 31 received from Mishra Dhatu Nigam Ltd., Hyderabad. The coating was done at Spraymet Surface Technologies Pvt. Ltd., Bengaluru. The surface of the substrate metal was roughened before coating for better bonding between the metal substrate and HA coating. Surface roughening was done by grit blasting with $\mathrm{Al}_{2} \mathrm{O}_{3}$ of grit size 24 . The roughened Ti 12 and Ti 31 samples were then washed with water followed by alcohol before plasma coating.

In plasma spray, a direct current was used to generate arc to produce high-temperature ionized plasma jet. The spray gun included throated tungsten carbide cathode enclosed by a water cooled copper cathode, with constant flow of plasma genic gas in the intervening space. The arc is struck between anode and cathode. The flame was fed with a continuous flow of inert gas, which was ionized by the DC arc. The torch nozzle accelerated the ionized gas with high velocity $(>800 \mathrm{~m} / \mathrm{s})$ and temperature $(12,000-16,000 \mathrm{~K})$. The powder coating material was fed into the ionized 
stream by feeder using gravimetric feed methodology with powder feeding rate of $8 \mathrm{~g} / \mathrm{min}$, where it was heated and thrust toward the substrate. The coating was carried out separately using four gas atmospheres: argon, argon/hydrogen, nitrogen, and nitrogen/ hydrogen. Here, argon and nitrogen served as primary gasses and hydrogen acted as the secondary gas. A pressure of $0.76 \mathrm{MPa}$ for primary gas (argon and nitrogen) and $0.069 \mathrm{MPa}$ for secondary gas of $10 \%$ volume (hydrogen) was applied to get desired plasma jet. The procedure was adjusted to produce a thickness of 100 microns with arc current $600 \mathrm{~A}$ and arc voltage $40 \mathrm{~V}$. The standoff distance between the substrate and the jet was maintained at $8 \mathrm{~cm}$.

\section{Scanning electron microscopy study}

The study was intended to understand the microstructure of HA coated in the different plasma atmosphere. For this purpose, analytical SEM-JEOL JSM-6380 LA model was used. The structure of HA surface of all the samples coated in argon, argon/hydrogen, nitrogen and nitrogen/hydrogen atmosphere were studied. The study samples were sputter coated with platinum before SEM study.

\section{X-ray diffraction}

The qualitative and quantitative information of all the HA coated samples under different gas atmospheres were obtained through X-ray diffraction to reveal detailed information about chemical composition, crystallography, and structure. The XRD studies were carried out on a JEOL-JDX-8P diffractometer. A scan speed of $2^{\circ} / \mathrm{min}$ was employed over $2 \theta$ angle range of $20^{\circ}-60^{\circ}$.

\section{RESULTS}

\section{Plasma coating}

During plasma spray coating, the hot gas jet created by the plasma arc expands, and HA powder accelerates toward the metal substrate. The particles then impact, deform, and resolidify to form the coating. A high degree of particle melting and relatively high particle velocity of plasma gas lead to higher deposit density and bond strength. A careful control of the operational spray parameters to prevent decomposition of HA is necessary..$^{[9,10]}$ Plasma spraying is easy to operate. However, during coating, the crystallinity of the HA decreases, in addition, there is change in the phase composition and introduction of residual stresses due to the high temperature involved in the process. ${ }^{[11-13]}$ Tricalcium phosphate (TCP), tetra calcium phosphate (TTCP), and $\mathrm{CaO}$ are the nonapatite phases of HA These form along with a mixture of crystalline and amorphous phases of $\mathrm{Ca}_{3}\left(\mathrm{PO}_{4}\right)_{2}$ on plasma spraying of implant. TCP and TTCP may be contributing to the implant instability because of the enhanced resorption of HA. ${ }^{[14,15]}$ Lower dissolution rate can be achieved by coating HA with lower crystallinity. ${ }^{[16-18]}$ The influence of plasma coating atmosphere on microstructure, composition, and crystallinity was conducted in the present study.

\section{X-ray diffraction studies}

The phase composition of the HA coatings documented was considerably different because of various process parameters of plasma spray and high thermal exchange between the plasma zone, powder particles, and the substrate metal. ${ }^{[19]}$ When the powder particles are injected into the plasma jet, the surface of the powder particles melt within a few microseconds. The high-temperature stream of droplets is impacted to the substrate surface to form coatings. Quick solidification of droplets takes place because of the rapid dissipation of heat to the substrate. This may induce amorphous HA on the surface of the substrate. Furthermore, it was found from the equilibrium phase diagram of CaO- $\mathrm{P}_{2} \mathrm{O}_{5}-\mathrm{H}_{2} \mathrm{O},{ }^{[20]}$ the decomposition of $\mathrm{HA}$ take place during the high-temperature process.

The high decomposition of HA and formation of any new phases were studied using X-ray diffraction profiles of HA coatings on Ti 12 and $\mathrm{Ti} 31$ presented in Figure 2. Furthermore, using these XRD patterns, the crystallinity of the coatings was also measured. For this purpose, highly crystalline HA feedstock was used as reference standard. Following equation ${ }^{[21-24]}$ was used for calculating crystallinity.

$$
\text { Crystallinity }(\%)=\frac{\sum \mathrm{A}_{\mathrm{C}}}{\sum \mathrm{A}_{\mathrm{C}}+\sum \mathrm{A}_{\mathrm{A}}} \times 100
$$

Where $\Sigma A_{C}$ is the sum of the areas under all the crystalline peaks of feedstock $H A$, and $\Sigma A_{A}$ is the sum of the areas under the amorphous peak after coating. The area of peaks of feedstock HA and the amorphous HA after coating were calculated between diffraction angle $2 \theta$ from 25 to $37^{\circ}$ as shown in Figure $2 a$ and $b$. Peak area calculations were performed using curve fitting with relative error estimation within $\pm 2 \%$ of the mean value. The crystallinity values are presented in Table 1. Least crystallinity was observed in the case of HA coating done under argon/hydrogen followed by nitrogen/hydrogen. In the case of argon and nitrogen atmospheres, the crystallinity value was between $61 \%$ and $63 \%$. 


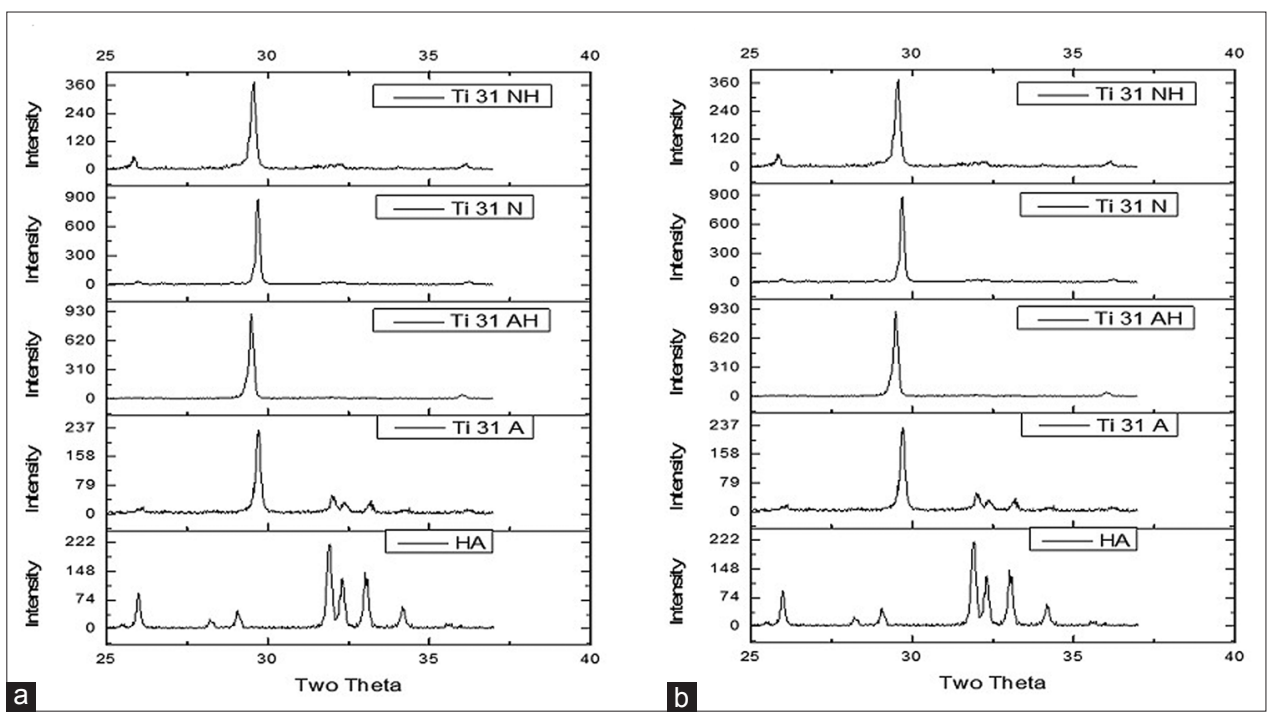

Figure 2: X-ray diffraction pattern between $2 \theta$ range from 25 to $37^{\circ}$ of initial hydroxyapatite (feedstock), and hydroxyapatite coated in argon, argon/hydrogen nitrogen, and nitrogen/hydrogen plasma atmospheres on (a) Ti 12, (b) Ti 31

\section{Scanning electron microscopy study}

It is important to determine the structure of a coating in plasma sprayed technique, which is a lamellar or layered splat structures with entrapped unmelted or resolidified particles, pores, oxide inclusions, grains, phases, and cracks. ${ }^{[25]}$ Therefore, it is essential to understand the features of the coating that were formed in the present study with the use of different plasma gas compositions. The change, if any that had taken place during coating was investigated using SEM. Figures 3-6 are the SEM micrographs of the HA coating carried out under argon, argon/hydrogen, nitrogen, and nitrogen/hydrogen plasma atmosphere on Ti 12 and Ti 31 substrates, respectively. The as-sprayed coating is composed of tightly adhering particles with complex forms [Figure 3], mostly pancake-like [Figures 4-6] or globular [Figures 5 and 6]. These particles are laid down on each other [Figures 4 and 6]. Micro-cracks [Figures 4a and 5] and pores [Figure 5a] are clearly visible.

\section{DISCUSSION OF RESULTS}

\section{Plasma coating of hydroxyapatite}

Plasma coating of HA is the commonly used technique of surface modification for dental and medical implants. The ability of the flame to melt powder particle depends on the plasma gas atmosphere. When the gas passes through the arc a large amount of gaseous expansion takes place, this makes the carrier gas stream to pass through the arc at a speed of sound. ${ }^{[26]}$

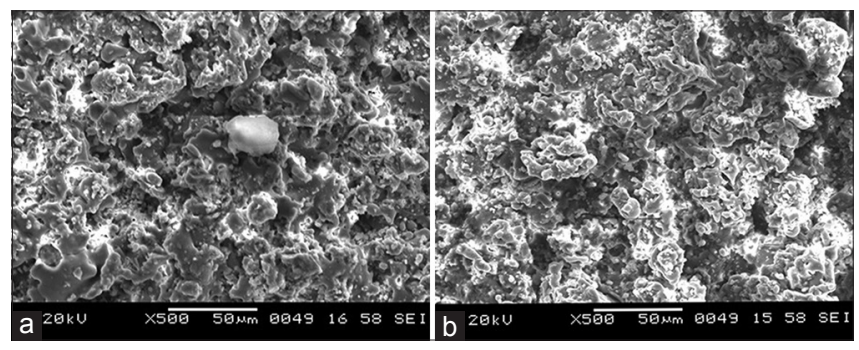

Figure 3: Microstructure of hydroxyapatite coated in argon atmosphere on (a) $\mathrm{Ti} 12$, (b) $\mathrm{Ti} 31$
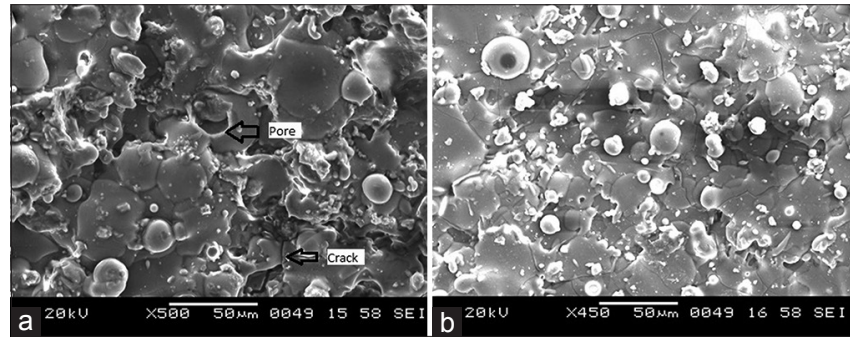

Figure 4: Microstructure of hydroxyapatite coated in argon/hydrogen atmosphere on (a) Ti 12, (b) Ti 31

\begin{tabular}{lc} 
Table 1: Crystallinity of hydroxyapatite coating \\
\hline Sample & Crystallinity (\%) \\
\hline Ti 12 argon/hydrogen & 33 \\
Ti 31 argon/hydrogen & 42 \\
Ti 12 nitrogen/hydrogen & 58 \\
Ti 31 nitrogen/hydrogen & 48 \\
Ti 12 argon & 63 \\
Ti 31 argon & 63 \\
Ti 12 nitrogen & 62 \\
Ti 31 nitrogen & 61 \\
\hline
\end{tabular}

Process control of plasma-sprayed HA coatings on titanium and the Ti-6Al-4V prosthesis is essential 


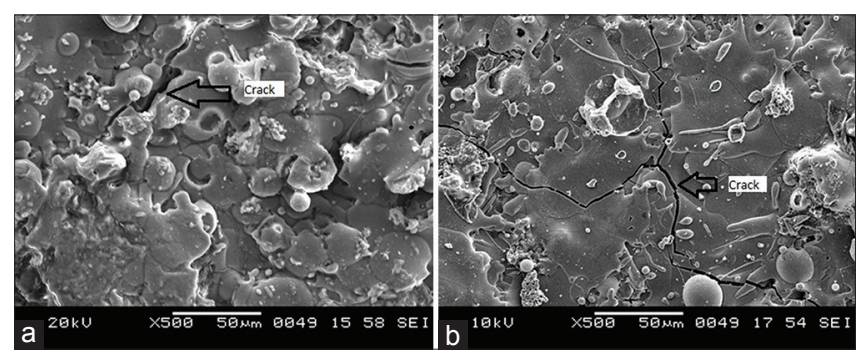

Figure 5: Microstructure of hydroxyapatite coated in nitrogen atmosphere on (a) Ti 12, (b) Ti 31

for improving the quality of the implants for their successful osseointegration. The HA coating prepared from calcined HA were highly porous and lacking in intimate lamellar contact. The spheroidal powders produced coating with porous porosity. ${ }^{[27]}$ Hence, attempts are always made to correlate the interaction between HA particles with various process parameters and in turn their biological properties. ${ }^{[22,28-34]}$ The properties of the coatings are controlled by regulating various plasma spray parameters. The plasma working gas composition remains same during plasma spray process and is not a basic parameter that is changed during the coating process. However, it is considered to be an important parameter that has the influence on coating properties ${ }^{[26]}$ For example, a mixture of argon and hydrogen gives a good coating. Furthermore, without hydrogen, the powder particles bounce back from the flame instead of entering it. Plasma work gas composition also influences the thickness of the coating. For example, the use of nitrogen as the carrier gas results in a thicker coating compared to the use of argon. Therefore, one can expect the possibilities of plasma gas composition having a significant role on the properties of the HA coating regarding phase constitution, porosity, the degree of crystallinity, bonding, microstructure, surface roughness, hardness, and others. Keeping these aspects in mind, the present study was carried out.

The main thrust of the present plasma spray study was to characterize the coating on Ti 12 and Ti 31 using different plasma forming gas compositions, namely, argon, argon/hydrogen, nitrogen, and nitrogen/hydrogen.

\section{Microstructure}

When argon atmosphere was as the coating environment, the as-sprayed HA coating was found to be composed of tightly adhering particles showing complex forms as presented in Figure 3. The coatings under other atmospheres mostly showed pancake-like deposits as shown in Figures 4-6, along with globular

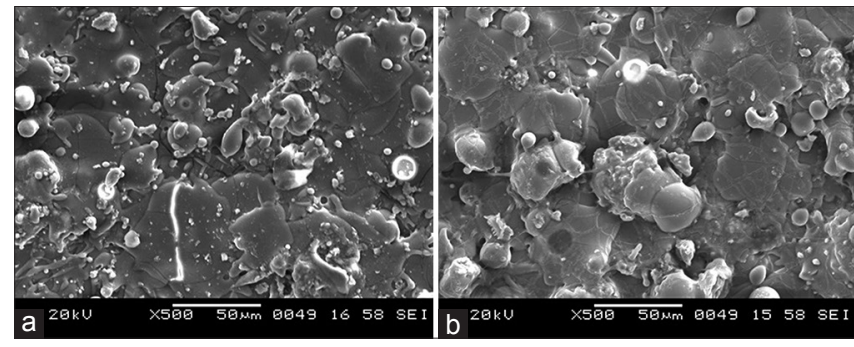

Figure 6: Microstructure of hydroxyapatite coated in nitrogen/ hydrogen atmosphere on (a) Ti 12, (b) Ti 31

particles as shown in Figures 5 and 6. These particles are laid down on each other as shown in Figures 4-6. Micro-cracks and pores were clearly visible, which can be seen from the arrows embedded in the micrographs $4 \mathrm{a}$ and 5 .

The argon plasma coated HA showed a different form of microstructure compared to the microstructures observed in other atmospheres. The microstructure looks complicated and appears to be rough as shown in Figure 3. In this particular case, it seems that the HA particles have not reached sufficiently high fusion temperature compared to other atmospheres. Hence, on coating and subsequent cooling and coalescence on the substrate, the fused HA droplets have not sufficiently spread into splat layers because of less fluidity. Instead, the molten HA was confined to the particular region of the coating area. In other atmospheres because of sufficient fusion of HA particles, there was good spreading and coalescence between the whereby layers and appear smooth. This can be seen from the Figures 4-6 for argon/hydrogen, nitrogen, and nitrogen/hydrogen coatings, respectively.

The difference in microstructure can be attributed to the high velocity and viscosity $\left(21 \mathrm{Nsm}^{-2}\right)$ of argon gas. This makes the powder bounce back from the flame and prevents it from entering into the core of the plasma flame where the temperature is higher compared to the periphery region. Hence, the particles of HA are not heated to the sufficiently high temperature and will be less fluid. Therefore, they do not spread sufficiently on the coating. This situation does not arise when hydrogen gas is used along with argon. The hydrogen has low viscosity $\left(8.35 \mathrm{Nsm}^{-2}\right)$. This reduces the bounce back tendency of powder particles as they enter the core of the plasma flame. The hydrogen also increases the enthalpy because of its diatomic structure. It has high collisional cross-section related to its mass compared to argon, and hence, it increases the contact rate of HA powder with the 
plasma gas. The bounce back tendency is also less in the case of nitrogen as its viscosity is $16.7 \mathrm{Nsm}^{-2}$, which is less than argon. Therefore, the microstructure observed in the argon atmosphere is different from the microstructures of other atmospheres of the present study. Furthermore, the enthalpy of plasma gas compositions is least for argon atmosphere compared to other atmospheres.

Besides the morphological features, another important observation that came out while studying the coatings under SEM was the presence of micro-cracks both on the surface and deeper inside the coatings. Figures 4-6 show some typical micro-cracks. These micro-cracks can be attributed to the thermal expansion mismatch between the coating and the substrate. The coefficient of thermal expansion of HA particle is reported to be $13.8 \times 10^{-4}{ }^{\circ} \mathrm{C}^{-1}$, while that of $\alpha$ titanium is $8.7 \times 10^{-4 \circ}$ $\mathrm{C}^{-1}$. On cooling from the plasma coating temperature, HA will tend to contract much more than the titanium substrate. Since the two are bounded, the slowly contracting titanium will resist the dimensional change of rapidly contracting HA. This sets up residual stresses within the HA, leading to the formation of micro-cracks. In the argon atmosphere, no micro-cracks were observed. The temperature of plasma flame is higher in argon/hydrogen, nitrogen/hydrogen, and nitrogen compared to argon, and hence, more thermal stresses are involved during coating and subsequent cooling. Therefore, a careful control of the plasma gas coating temperature and the coefficient of thermal expansion/ contraction mismatch between the substrate and HA is essential to reduce such cracks by thermal stresses.

\section{Crystallinity and phase analysis}

The crystallinity of HA coating plays a major role in plasma coated HA. Radin and Ducheyne ${ }^{[14]}$ have reported that phase composition and the crystallinity have control over the in vivo dissolution behavior. Well-crystallized HA is very stable, bio-inert, and has an inhibiting effect on cell proliferation.

The plasma spraying processes temperatures in the range of $6000-11,000^{\circ} \mathrm{K}$. As a result, during plasma spraying, HA powder may be wholly or partly melted. It is then quenched to room temperature in a fraction of a second when it hits the substrate. The high thermal conductivity of the metal substrate initially in contact with the molten HA favors the formation of an amorphous phase. ${ }^{[35]}$

For crystallinity determination, higher resolution diffractograms of HA coating under different atmospheres were compared with that obtained from the commercial HA used as the feedstock. As per the manufacturer's analysis, this material exhibits $97 \%$ crystallinity. This is used as reference standard for the present calculations.

In the study carried out by Medina Ledo et al. ${ }^{[36]}$ and Kweh et al., ${ }^{[37]}$ the relative crystallinity was assessed and determined by comparing intensity of the main peak, that is (211) peak, of HA powder with the intensity of (211) peak of the reference HA standard according to;

Crystallinity $(\%)=\frac{\operatorname{HA}(211)}{\operatorname{HAs}(211)} \times 100$

Where HAs(211) is the integrated intensity of the HA standard and $\mathrm{HA}(211)$ is the integrated intensity of the HA powder under study.

In the present study, the crystallinity of the coatings was evaluated using following equation, which was used in some previous works; ;21-26,38]

$$
\text { Crystallinity }(\%)=\frac{\sum \mathrm{A}_{\mathrm{C}}}{\sum \mathrm{A}_{\mathrm{C}}+\sum \mathrm{A}_{\mathrm{A}}} \times 100
$$

In this particular method of measuring crystallinity, all the major peaks of HA including main (211) peak were used for calculation of crystallinity. This was considered to give better results than using just one main (211) peak as in the method of Medina Ledo et al. ${ }^{[36]}$ In the above equation, $\Sigma \mathrm{A}_{\mathrm{C}}$ is the total area under all the peaks in the $2 \theta$ range of $25^{\circ}-37^{\circ}$ of the XRD profile of the initial HA (feedstock), which is shown in Figure 7. $\Sigma \mathrm{A}_{\mathrm{A}}$ is the total area of the amorphous HA coating within the range of $25^{\circ}$ and $37^{\circ}$ shown in Figure 2a and b for Ti 12 and Ti 31 substrates, respectively. For HA most of the major peaks appear between $25^{\circ}$ and $37^{\circ}$.

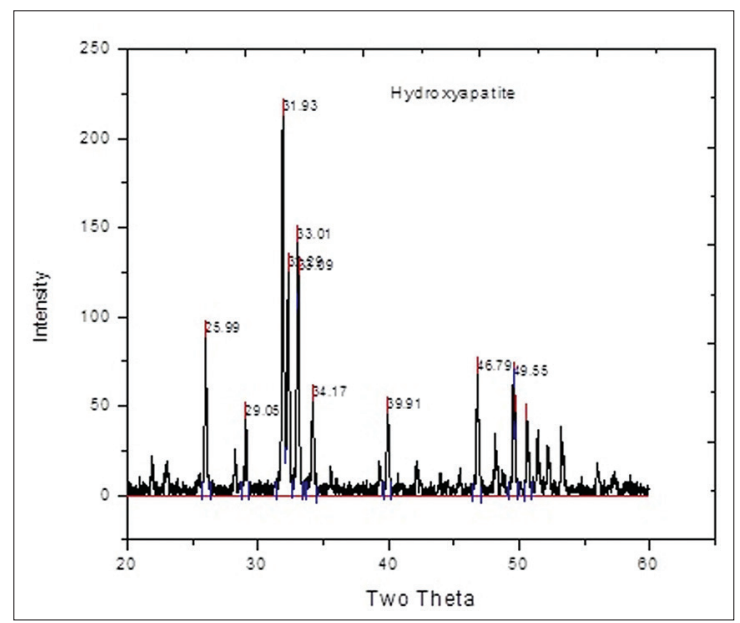

Figure 7: X-ray diffraction pattern of hydroxyapatite (Feedstock) 
The results of the crystallinity estimation for all the coating atmospheres are presented in Table 1. Crystallinity was found to be considerably less than that of the feedstock for all HA under different atmospheres. Crystallinity is nearly $60 \%$ in the case of argon, and nitrogen atmospheres. Coating done under argon/hydrogen atmosphere showed the least crystallinity of 33 and $42 \%$ with $\mathrm{Ti} 12$ and $\mathrm{Ti}$ 31 substrates, respectively. The nitrogen/hydrogen atmosphere coating showed intermediate crystallinity of 58 and $48 \%$ with $\mathrm{Ti} 12$ and $\mathrm{Ti} 31$, respectively. The lower crystallinity values in the case of argon and nitrogen atmosphere with secondary gas hydrogen are attributed to the high plasma flame temperature. Amorphous coatings do not have distinct melting, unlike its crystalline counterpart. They also exhibit glass transition temperature range. Therefore, the amorphous phase flow at a temperature lower than the melting point of its crystalline counterpart and fill the voids between the neighboring splats making the coating smooth and glassy.

It can be said that there is no discernible difference in the crystallization path among HA powder and HA coating on $\mathrm{Ti}$ and Ti alloy substrates. The Ti-alloy substrate, as well as HA films, undergo thermal heat treatment, whereby $\beta$ tricalcium phosphate is formed. In such a study by Cirilli et al. ${ }^{[39]}$ it has been shown that such a transformation leads to the formation of intermediate layer $\mathrm{TiO}_{2}$ and/or $\mathrm{CaTiO}_{3^{\prime}}$

$\mathrm{TiO}_{2}+\mathrm{Ca}_{10}\left(\mathrm{PO}_{4}\right)_{6}(\mathrm{OH})_{2} \rightarrow \mathrm{CaTiO}_{3}+3 \mathrm{Ca}_{3}\left(\mathrm{PO}_{4}\right)_{2}+\mathrm{H}_{2} \mathrm{O}$

For the analysis of composition and phases present in HA coatings, the diffraction patterns were analyzed by X'Pert High Score software. The XRD profile of the feedstock shown in Figure 7 was found to be of $\mathrm{Ca}_{10}\left(\mathrm{PO}_{4}\right)_{6}(\mathrm{OH})_{2}$ - calcium phosphate hydroxide, which matched with JCPDS file no. 72-1243. In addition to HA, the XRD profiles of coatings presented in Figure 2 showed the presence of $\beta$ tricalcium phosphate $\left[\mathrm{Ca}_{3}\left(\mathrm{PO}_{4}\right)_{2}\right]$, TTCP $\left[\mathrm{Ca}_{4}\left(\mathrm{PO}_{4}\right) \mathrm{O}\right]$, and $\mathrm{CaO}$. The spectral lines of these compounds matched with JCPDS file no. 9-0169, 70-1379, and 75-0264, respectively. The XRD patterns also showed incorporation of $\mathrm{CO}_{3}{ }^{2-}$ groups into the HA coatings. HA coated samples also showed relatively weak diffraction lines for TiH (JCPDS file no. 01-078-2215), $\mathrm{H}_{2}\left[\mathrm{Ti}\left(\mathrm{PO}_{4}\right)_{2}\right]$ (JCPDS 021-0392), $\mathrm{Ca}_{4} \mathrm{Ti}_{3} \mathrm{O}_{10}$ (JCPDS file no. 01-089-1385 and 01-014-0152), $\mathrm{CaV}_{4} \mathrm{O}_{9}$ (01-070-1325), $\mathrm{TiO}_{2}$, and vanadium oxide. These indicate that the metal constituents have chemically reacted with calcium and phosphorous of HA at high temperature. In the present study, these findings cannot be claimed with certainty as the peaks obtained were very weak. However, there is a possibility of the formation of the above-mentioned compounds and is supported by earlier studies as well. ${ }^{[39-42]}$

As compared to feedstock, a shift in the $2 \theta$ diffraction angle was observed in HA coatings. The shift observed was to the lower side of $2 \theta$ angles of raw material. This change in angles is attributed to the lattice strain incorporated during coating because of thermal stress, which is common in hexagonal close-packed structures. The average lattice strain and crystallite size calculated for the diffraction lines between $25^{\circ}$ and $37^{\circ}$ of the coatings are shown in Table 2 . The average crystallite size of the feedstock powder and the HA coating was determined using following equation: ${ }^{[43,44]}$

$t=\frac{0.9 \lambda}{\mathrm{B} \operatorname{Cos} \theta_{\mathrm{b}}}$

Where $t$ is the thickness of the crystal, $\lambda$ is the wavelength, and $\theta_{b}$ is the Bragg angle. $B$ is calculated by:

$$
B=\sqrt{\left(B_{\mathrm{M}}^{2}+B_{\mathrm{S}}^{2}\right)}
$$

Where $B_{M}$ is the full-width half maximum (FWHM) of the diffraction line, and $\mathrm{B}_{\mathrm{S}}$ is the FWHM of the machine background.

\section{CONCLUSION}

1. Plasma gas composition has control over the melting of HA particles. Control of the plasma gas temperature is essential to reduce the micro-cracks by thermal stresses

2. Plasma flame temperature has an influence on the crystallinity of HA coating.

3. The crystallinity and morphology were affected by spraying atmosphere. The crystallinity

\begin{tabular}{|c|c|c|}
\hline Sample & Crystallite size $(\mu \mathrm{m})$ & Lattice strain (\%) \\
\hline Ti 12 argon/hydrogen & 67.4 & 0.450 \\
\hline Ti 31 argon/hydrogen & 64.2 & 0.474 \\
\hline Ti 12 nitrogen/hydrogen & 106.2 & 0.340 \\
\hline Ti 31 nitrogen/hydrogen & 74.5 & 0.337 \\
\hline Ti 12 argon & 74.4 & 0.310 \\
\hline Ti 31 argon & 62.1 & 0.356 \\
\hline Ti 12 nitrogen & 75.9 & 0.497 \\
\hline Ti 31 nitrogen & 58.1 & 0.435 \\
\hline
\end{tabular}


and morphology were affected by spraying atmosphere. The plasma gas atmosphere of argon and nitrogen gas atmosphere showed the highest crystallinity compared to argon-hydrogen and nitrogen-hydrogen"

4. The high temperature of plasma coating and thermal stresses have led to the shift in the $2 \theta$ angle of $\mathrm{HA}$ coating and incorporation of lattice strain.

5. Reaction products such as $\mathrm{CaTi}_{3} \mathrm{O}_{4^{\prime}} \mathrm{CaV}_{4} \mathrm{O}_{9}, \mathrm{Ca}_{4} \mathrm{Ti}_{3} \mathrm{O}_{4}$, and $\mathrm{H}_{2}\left[\mathrm{Ti}\left(\mathrm{PO}_{4}\right)_{2}\right]$ formed support chemical bonding between HA and the metal substrate.

\section{Financial support and sponsorship}

Nil.

\section{Conflicts of interest}

There are no conflicts of interest.

\section{REFERENCES}

1. Ducheyne P, Beight J, Cuckler J, Evans B, Radin S. Effect of calcium phosphate coating characteristics on early post-operative bone tissue ingrowth. Biomaterials 1990;11:531-40.

2. Campbell AA, Fryxell GE, Linehan JC, Graff GL. Surface-induced mineralization: A new method for producing calcium phosphate coatings. J Biomed Mater Res 1996;32:111-8.

3. Lacefield WR. Hydroxyapatite coatings. Ann N Y Acad Sci 1988;523:72-80.

4. Berndt CC, Haddad GN, Farmer AJD, Gross KA. Thermal spraying for bioceramic applications. Mater Forum 1990;14:161-73.

5. Bernecki TF. Quality control of hydroxyapatite coating: Purity and crystalline determination. In: Salsbury RL, editor. National Thermal Spray; Conference, 1991; Pennsylvania: ASM International;1991, p. 471-3.

6. Hanif A, Quereshi S, Sheik Z, Rashid H. Complications in implant dentistry. Eur J Dent 2017;11:135-40.

7. Crawmer DE. Thermal spray processes. In: Davis JR, editor. Hand Book of Thermal Spray Technology. ASM International; Materials Park, Ohio; 2004. p. 54-76.

8. Wise DL, Trantola DJ, Altobelli DE, Yaszemski MJ, Gresser JD, Schwartz ER. Biomaterials in Orthopaedics. Basel: Marcel Dekker; 2004. p. 401-23.

9. Dyshlovenko S, Pawlowski L, Roussel P, Murano D, Le Maguer A. Relationship between plasma spraying operational parameters and microstructure of hydroxyapatite coatings and powder particles sprayed into water. Surf Coat Technol 2006;200:3845-55.

10. Gledhill HC, Turner IG, Doyle C. Direct morphological comparison of vacuum plasma sprayed and detonation gun sprayed hydroxyapatite coatings for orthopaedic applications. Biomaterials 1999;20:315-22.

11. Gross KA, Berndt CC, Herman H. Amorphous phase formation in plasma-sprayed hydroxyapatite coatings. J Biomed Mater Res 1998;39:407-14.

12. Zyman Z, Weng J, Liu X, Zhang X, Ma Z. Amorphous phase and morphological structure of hydroxyapatite plasma coatings. Biomaterials 1993;14:225-8.

13. Chen J, Tong W, Cao Y, Feng J, Zhang X. Effect of atmosphere on phase transformation in plasma-sprayed hydroxyapatite coatings during heat treatment. J Biomed Mater Res 1997;34:15-20.

14. Radin SR, Ducheyne P. Plasma spraying induced changes of calcium phosphate ceramic characteristic and the effect on in vitro stability. J Mater Sci Mater Med 1992;3:33-42.

15. Das S, Jhingaran R, Bains VK, Madan R, Srivastava R, Razvi I. Socket preservation by beta tri-calcium phosphate with collagen compared to plate-rich fabrin: A clinico-radiographic study. Eur J Dent 2016;10:264-76.

16. Heimann RB, Wirth R. Formation and transformation of amorphous calcium phosphates on titanium alloy surfaces during atmospheric plasma spraying and their subsequent in vitro performance. Biomaterials 2006;27:823-31.

17. Maxian SH, Zawadsky JP, Dunn MG. Mechanical and histological evaluation of amorphous calcium phosphate and poorly crystallized hydroxyapatite coatings on titanium implants. J Biomed Mater Res 1993;27:717-28.

18. Klein CP, Wolke JG, de Blieck-Hogervorst JM, de Groot K. Features of calcium phosphate plasma-sprayed coatings: An in vitro study. J Biomed Mater Res 1994;28:961-7.

19. Yang $C Y$, Wang BC, Chang E, Wu BC. Bond degradation of plasma sprayed HA coating/Ti-6Al-4V alloy interface: An in vitro study. J Mater Sci Mater Med 1995;6:258-65.

20. Reboud PV. CaO-P2O5-H2O quasi-binary system. Ann Chim 1973;8:381-90.

21. Tsui YC, Doyle C, Clyne TW. Plasma sprayed hydroxyapatite coatings on titanium substrates. Part 1: Mechanical properties and residual stress levels. Biomaterials 1998;19:2015-29.

22. Sun L, Christopher CB, Clare PG. Phase, structural and microstructural investigations of plasma sprayed hydroxyapatite. Mater Sci Eng 2003;360A: 70-84.

23. McPherson R, Gane N, Bastow TJ. Structural characterization of plasma sprayed hydroxyapatite. J Biomed Mater Res 1995;6:327-34.

24. Crawmer DE. Coating structure, properties, and materials. In: Davis JR, editor. Hand Book of Thermal Spray Technology.ASM International; Materials Park; Ohio; 2004. p. 47-53.

25. LeGeros JP, LeGeros RZ, Burgess A, Edwards B, Zitelli J. X-ray diffraction method for the quantitative characterization of calcium phosphate coatings. In: Parr JE, Horowitz E, editor. Characterization and Performance of Calcium Phosphate Coatings for Implants. Philadelphia: ASTM; 1994. p. 33-42.

26. Yang Y, Ong JL. Plasma-sprayed hydroxyapatite-coated and plasma-sprayed titanium-coated implants. In: Yaszemski MJ, Trantolo DJ, Lewandrowski KU, Hasirci V, Altobelli DE, Wise DL, editors. Biomaterials in Orthopedics. Marcel Dekker; New York; 2004 p. 401-24.

27. Cheang P, Khor KA. Influence of powder characteristics on plasma sprayed hydroxyapatite coatings. J Therm Spray Technol 1996;5:310-6.

28. Khor KA, Gu YW, Quek CH, Cheang P. Plasma spraying of functionally graded hydroxyapatite/T-6Al-4V coating. Surf Coat Technol 2003;168:195-200.

29. Deram V, Minichiello C, Vannier RN, Le Maguer A, Pawlowski L, Murano DL. Microstructural characterization of plasma sprayed hydroxyapatite coatings. Surf Coat Technol 2003;166:153-9.

30. Hauxia JI, Ponton CB, Marquis PM. Microstructural characterization of hydroxyapatite on titanium. J Mater Sci Mater Med 1992;3:283-7.

31. Liu X, Zhao X, Fu RK, Ho JP, Ding C, Chu PK, et al. Plasma-treated nanostructured Tio(2) surface supporting biomimetic growth of apatite. Biomaterials 2005;26:6143-50.

32. Park E, Condrate RA Sr., Hoelzer DT, Fischman GS. Interfacial characterization of plasma-spray coated calcium phosphate on Ti-6Al-4V. J Mater Sci Mater Med 1998;9:643-9.

33. Oh IH, Nomura N, Chiba A, Murayama Y, Masahashi N, Lee BT, et al. Microstructures and bond strengths of plasma-sprayed hydroxyapatite coatings on porous titanium substrates. J Mater Sci Mater Med 2005;16:635-40.

34. Lee IS, Kim HE, Kim SY. Studies on calcium phosphate coating. Surf Coat Technol 2000;131:181-6.

35. Davis JR. Introduction to thermal spray processing. In: Davis JR, editor. Hand Book of Thermal Spray,ASM International; Materials Park; Ohio; 2004. p. 3-13

36. Medina Ledo H, Thackray AC, Jones IP, Marquis PM, Macaskie LE, Sammons RL, et al. Microstructure and composition of biosynthetically synthesised hydroxyapatite. J Mater Sci Mater Med 2008;19:3419-27.

37. Kweh SW, Khor KA, Cheang P. Plasma-sprayed hydroxyapatite (HA) coatings with flame-spheroidized feedstock: Microstructure and mechanical properties. Biomaterials 2000;21:1223-34.

38. Wang J, Layrolle P, Stigter M, de Groot K. Biomimetic and electrolytic calcium phosphate coatings on titanium alloy: Physicochemical characteristics and cell attachment. Biomaterials 2004;25:583-92.

39. Cirilli F, Kaciulius S, Mattogno G. Surface analysis of biocompatible hydroxyapatite coatings on titanium. In: Nyborg L, Olefjort BD, editors. Biomaterials Proceedings ECASIA 97. Wiley, Chichester, 1997.

40. Hauxia JI, Ponton CB, Marquis PM. Microstructural characterization 
Kotian, et al.: X-ray diffraction of plasma coated hydroxyapatite

of hydroxyapatite on titanium. J Mater Sci Mater Med 1992;3:283-7.

41. Ducheyne P, Van Raemdonck W, Heughebaert JC, Heughebaert M. Structural analysis of hydroxyapatite coatings on titanium. Biomaterials 1986;7:97-103.

42. Yan L, Leng Y, Weng LT. Characterization of chemical inhomogeneity in plasma-sprayed hydroxyapatite coatings. Biomaterials
2003;24:2585-92.

43. Zhang Y, Stewart JM, Moroson B, Hubbard CR. Ceramic Transactions. In: Fuller FR, Hausner H, Messing GL, editor. Ceramic Powder Science. Westerville, OH: American Ceramic Society; 1998. p. 1192.

44. Cullity CD. Elements of X-Ray Diffraction. Monlo Park: Addison-Wesley; 1978. p. 99-105. 